\title{
Oral Fordyce's Granules and Serum Lipid Profile; any Relationship?
}

\author{
Ameena Ryhan Diajil \\ Assistant Prof., BDS, M.Sc., Ph.D. in Oral Medicine, University of Baghdad-Collage of Dentistry-Oral Diagnosis \\ Department-Oral Medicine
}

\begin{abstract}
Background: Sebaceous glands are normal structures of the skin, but may be ectopically found in the mouth, as oral Fordyce granules. They are located just beneath the overlying epithelium and are visible through the epithelium producing local elevations. It has been suggested that there is a relation between elevated lipid profile and the presence of these granules.

Method: A total of 130 individuals were included in this cross-sectional study, who were subjected to the oral examination for the presence \& scoring of oral Fordyce granules, then blood samples were taken. Case sheet involved, demographic information and medical history. Using specialized kits, lipids profile analysis was done on a fully automated spectrophotometric analyzer.

Results: Fordyce granules were recorded in $25 \%$ of cases, with males formed the majority of them. In both gender, lip was the most commonly affected sites.

Fordyce granules were observed in one-third of patients with systemic diseases.

The majority of cases with Fordyce granules, recoded normal triglyceride, HDL, LDL and VLDL levels, but one-fourth of patients with hyper cholesterol were seen with Fordyce granules. Chi-Square test showed no association between lipid profile $\&$ these granules.

A negative correlation was found between Fordyce granules number and cholesterol, HDL and LDL levels, although statistically non- significant.

Conclusion: Oral Fordyce granules were most frequently observed in the lips, with male gender and older age predilections. The current study did not support the association between oral Fordyce granules and serum lipid profile changes.
\end{abstract}

Keywords: Oral Fordyce granules, lipid profile.

\section{Introduction}

Sebaceous glands are normal structures of the skin but may also be found ectopically in the mouth, where they are referred to as oral Fordyce granules or ectopic sebaceous glands. ${ }^{1}$

Fordyce granules (FGs) are ectopic sebaceous glands located on the mucosal surface of the oral cavity which may be considered as a variation of normal anatomy ${ }^{2}$. These spots are typically present as small asymptomatic, multiple whitish, or yellowish 1-3-mm sized papules ${ }^{3-5}$. The glands are located just beneath the overlying epithelium and often produce a local elevation of the epithelium ${ }^{6}$.

Fordyce granules are often discovered during routine dental examinations which are mainly seen on the labial and buccal mucosa in adults?

The common site for Fordyce's granules is vermillion border and lips, with buccal mucosa particularly inside the commissures and retro molar region has also been suggested as common site ${ }^{8}$.

Studies reported that FGs are not usually visible in 
children, and tend to appear at about age 3, then during puberty and become more obvious in later adulthood ${ }^{8}$.

Some studies showed that they are more prominent in males while, other studies reported no significant difference in the prevalence between both genders?

Few patients were seen with hundreds of granules while the majorities were seen with only one or two.

Etiologically, it is not known what causes FGs, but some studies have linked their development to hormonal changes and genetic; and they are not known to be associated with any disease or illness and are of cosmetic concern only. While, some authorities believed that FGs are seen in some rheumatic disorders and in hereditary non-polyposis colorectal cancer syndrome ${ }^{10}$.

Lipid is an important for normal cell function, with normal level of cholesterol is a vital component of cell membranes structure. It is also involved in many enzymatic processes and genetic stability ${ }^{11,12}$.

Considering lipid profile, total cholesterol (TC) measures all the cholesterol in all the lipoprotein particles. High-density lipoprotein (HDL) measures the cholesterol in HDL particles takes up excess cholesterol and carries it to the liver for removal. Low-density lipoprotein (LDL) measures the cholesterol in LDL particles, it deposits excess cholesterol in walls of blood vessels, which can contribute to atherosclerosis. This can be calculated using the results of total cholesterol, HDL and triglycerides (TG). Triglycerides measure all the triglycerides in all the lipoprotein particles; most of it is in the very low-density lipoproteins (VLDL) ${ }^{13}$.

A study showed that individuals with an elevated lipids profile tend to have oral FGs and may be with higher numbers compared to normal range of lipid profile $^{14}$.

A very few research in this topic, and to date, no study has been published to describe the clinical manifestation of FGs and lipids profile in Iraqi population. Thus, the present study was designed to investigate the prevalence and relationship between serum lipids profile with oral FGs in relation to demography and medical history of patients.

\section{Material and Method}

The protocol of this observational cross sectional study was reviewed and approved by the Ethical Committee of the Oral Diagnosis Department of the
Collage of Dentistry- University of Baghdad. The written informed consents were obtained from all recruits, after clearly explained the protocol to the participants, and detailed information about the study and the blood samples collection.

From September 2019 to March 2020,a total of 130 participants attended Al-America primary health center in Al-America sector in Baghdad, who were sent for serum lipids profile tests, were enrolled in this study. During their follow up, those patients were already asked to fast overnight approximately 8-12 hours to test their lipids profile.

The subjects were excluded if they had a major illness in recent past or were taking or had previously taken any medications known to influence lipid levels metabolism in the past 6 months.

Case sheets were filled for the patients who gave their consent form to participate in this study. Case sheet includes demographic information such as age, gender, marital status, number of children. The individuals were also questioned about systemic diseases.

During the same visit of taking the blood samples, oral examination of each participant's mouth, was performed by the oral medicine specialist (author) focusing on the presence of the FGs in the oral cavity. Recording their location and the number, using five scoring system: Group 1: 0 granules, Group 2: up to 10 granules, Group 3: up to 30 granules, Group 4: 30 to 100 granules and Group 5: more than 100 granules.

Under sterile conditions, 4-5 milliliters of venous blood was collected after an overnight fast, from antecubital vein in vacuumed blood collection tubes with gel and were labeled with an individual patient ID, then serum was extracted after centrifugation for 15 minutes (2000 rpm).

Estimation of serum lipids profile was done on a fully automated analyzer based on spectrophotometric principle using enzymatic colorimetric method kits. The serum lipid profile was analyzed on the same day of the withdrawal of blood samples.

Plasma levels of TC, TG, HDL were estimated using enzymatic colorimetric test (Linear Chemicals S.L.U, SPAIN). VLDL and LDL were calculated using the formula given below: $\mathrm{VLDLC}=\mathrm{TG} / 5$

$$
\mathrm{LDLC}=\mathrm{TC}-\mathrm{VLDLC}-\mathrm{LDLC}
$$


Statistical Analysis: Data analysis was performed using Statistical Package of Social Sciences software version 20 .

Descriptive statistics were obtained for all variables in the study with means, standard deviations and standard error of mean (SEM) were applied as appropriate.

Analysis of variance (ANOVA), student T-test, ChiSquare test, Fisher's Exact and correlation coefficients tests were used. A p-value of less than 0.05 was considered to indicate statistical significance.

\section{Results}

1. Patients Demography: In this study, 130 participants were included, with an age range of 2079 years and a mean age of 51.4 years. Patients were divided into three age groups; 20-39, 40-59 and 6079 years, with the age group 40-59 years, formed the majority of patients, followed by the older age group 60-79 years.

The majority of patients were males 75 (57\%) with males mean age was 52.9 years. Females were younger than males with a mean age of 49.6 years.

2. Fordyce's granules distribution in the oral cavity: Thirty-two patients $(25 \%)$ out of 130 , were with FGs. Twenty- four (75\%) were recorded in the lips and 12 were recorded in the cheek (4 cases were with both lips and cheek). Considering the number of FGs, the majority of patients were with $\approx$ 10 granules per location, with only one patient was with more than 100 .

3. Fordyce's granules, Age, Gender, Medical history and Lipid profile tests: The mean age of males with FGs (54 years) which was higher than that of females with FGs (49.3 years).

Regarding gender, out of the 32 patients with FGs, 22 were males forming $69 \%$ and $10(31 \%)$ were females. In both gender, lips showed the most common oral sites for these granules. Considering males, 14 were with lips FGs and 8 were with cheek granules. Similarly, in females lips recorded more FGs (6 out of 10).

In the current study, the majority of participants were with systemic diseases $(90,69 \%)$ while rest $40(31 \%)$ were without any systemic diseases. The majority of patients $(54,42 \%)$ were previously diagnosed with hypertension, followed by both hypertension and diabetes mellitus $(23,18 \%)$ and only $13(10 \%)$ were with a diabetes mellitus only.

Considering gender, those with systemic disease, 55 were males and 35 were females. While those without any systemic diseases, 19 were males and 21 were females.

The majority of patients $(66 \% ; 21 / 32)$ with systemic diseases were with FGs, and all of them were with lips involvement, but only 3 cases with FGs, were without any systemic diseases.

As shown in Table (1), hypertensive patients showed higher mean cholesterol, triglyceride, HDL and VLDL compared to patients with diabetes and those suffered from both hypertension and diabetes mellitus together. While patients with both hypertension and diabetes showed higher mean values for LDL. Students t- test showed no significant difference between different systemic diseases in mean lipids value.

As shown in Table (2), a higher mean lipid value was seen in females in cholesterol and LDL, while higher means were seen in males in triglyceride, HDL and VLDL. However, t-test showed no significant differences.

Fordyce's granules, Cholesterol and Triglyceride

Both cholesterol and triglyceride levels were divided into 3 levels; normal range, border line and high range level, which subsequently scored as 0,1 and 2, respectively; Table (3).

One-fourth of cases with hyper cholesterol were seen with FGs; however, Chi-Square test showed no association between cholesterol level and oral FGs (1.214, df:2, $\mathrm{p}=0.545)$.

The majority of cases were with normal level, followed by high and then border line values.

The majority of FGs cases, were with normal triglyceride and $\approx 1 / 3$ of cases with higher triglyceride.Chi-Square test showed no association between triglyceride level and FGs (1.556, df:2, $\mathrm{p}=0.459$ ). Considering gender, the majority of males were seen with high level range of triglyceride compared to females.

Fordyce's granules, HDL, LDL and VLDL

High density lipoprotein, LDL and VLDL levels were divided into 2 scores; Table (4). Cases with 
FGs were commonly seen with normal HDL values, followed by the higher HDL levels; Chi-Square test showed no association between HDL and FGs (0.192, df: $1, p=0.661)$, although half of cases with hyper LDL were seen with FGs.

Similarly, LDL showed no association with presence of FGs (0.002, df:1, $\mathrm{p}=0.966)$; an equal number of FGs were seen in normal and high level scores.

Regarding VLDL, the majority of cases were within normal range values followed by the high values.

Although, the majority of both gender recorded normal VLDL, males were seen with higher VLDL values compared to females. FGs cases were nearly equally in number in normal and higher VLDL level. Chi square test showed no association between VLDL and FGs (0.761, df:1, p=0.383), although $\approx$ half of FGs cases were observed with high LDL levels.

4. Hyperglycemia: In this study, overlap records were seen in recording higher levels of lipids profile. Using just the higher lipid score values for the all 5 lipids, cases with higher levels of LDL and VLDL were commonly seen with positive FGs, followed by those with higher HDL, trichleseride and cholesterol.

However, Chi square test showed no association between the presence FGs and each type of lipid with its higher recorded levels $(0.457, \mathrm{df}=4, \mathrm{p}=0.978)$; Table (5).

Using cases with different types of hyperlipidemia to study the association with FG, Fisher's Exact Test showed no association between FGs and hyperlipidemia in only, one type of lipid, 2 types, 3 types, 4 types and all the 5 types of lipid profile $(\mathrm{P}=$ $0.65)$.

5. Correlations between study parameters: Using Pearson correlation, although no significant correlation was found between FG count and the five lipid profile values; there is a negative relations between FG number and cholesterol, HDL and LDL; Table (6).Also, a negative but no significant correlation was recorded between HDL and oral FGs, using the scores for each type of lipids ( $r=$ $-0.040, \mathrm{p}=0.664)$.

Table (1): Mean lipid values in patients with different systemic diseases.

\begin{tabular}{|c|c|c|c|c|c|}
\hline Lipid profile & Systemic disease & $\mathbf{N}$ & Mean & Std. Deviation & Std. Error Mean \\
\hline \multirow{3}{*}{ Cholesterol } & Hypertension and Diabetes & 19 & 200.11 & 42.76 & 9.81 \\
\hline & Diabetes & 12 & 192 & 40.94 & 11.82 \\
\hline & Hypertension & 46 & 203.26 & 55.47 & 8.18 \\
\hline \multirow{3}{*}{ Triglyceride } & Hypertension and Diabetes & 19 & 135.32 & 69.46 & 15.94 \\
\hline & Diabetes & 12 & 146.42 & 66.15 & 19.1 \\
\hline & Hypertension & 46 & 158.87 & 84.79 & 12.5 \\
\hline \multirow{3}{*}{ HDL } & Hypertension and Diabetes & 18 & 38.17 & 5.54 & 1.31 \\
\hline & Diabetes & 11 & 36 & 3.38 & 1.02 \\
\hline & Hypertension & 46 & 41.72 & 11.98 & 1.77 \\
\hline \multirow{3}{*}{ LDL } & Hypertension and Diabetes & 18 & 127.83 & 39.22 & 9.25 \\
\hline & Diabetes & 10 & 125.5 & 28.42 & 8.99 \\
\hline & Hypertension & 46 & 122.54 & 41.39 & 6.1 \\
\hline \multirow{3}{*}{ VLDL } & Hypertension and Diabetes & 18 & 26.06 & 13.76 & 3.24 \\
\hline & Diabetes & 11 & 29.15 & 11.12 & 3.35 \\
\hline & Hypertension & 45 & 35.09 & 25 & 3.73 \\
\hline
\end{tabular}


Table (2): Lipid profile in relation to gender in the study group

\begin{tabular}{|c|c|c|c|c|c|c|}
\hline Type of Lipids & Gender & No. & Mean & \pm SD & $\pm \mathrm{SE}$ & $t$ - test \\
\hline \multirow{2}{*}{ Cholesterol } & $\hat{\sigma}$ & 73 & 203.13 & 58.72 & 6.87 & \multirow{2}{*}{$\begin{array}{l}\mathrm{t}=-0.5 \\
\mathrm{df}=126 \\
\mathrm{p}=0.59\end{array}$} \\
\hline & q & 55 & 208.14 & 41.29 & 5.56 & \\
\hline \multirow{2}{*}{ Triglyceride } & $\delta$ & 73 & 160.32 & 92.95 & 10.87 & \multirow{2}{*}{$\begin{array}{l}\mathrm{t}=1.41 \\
\mathrm{df}=126 \\
\mathrm{p}=0.16\end{array}$} \\
\hline & 우 & 55 & 139.18 & 70.14 & 9.45 & \\
\hline \multirow{2}{*}{ HDL } & 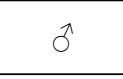 & 69 & 40.71 & 9.20 & 1.10 & \multirow{2}{*}{$\begin{array}{l}\mathrm{t}=1.00 \\
\mathrm{df}=121 \\
\mathrm{p}=0.31\end{array}$} \\
\hline & q & 54 & 38.94 & 10.25 & 1.39 & \\
\hline \multirow{2}{*}{ LDL } & $\hat{o}$ & 69 & 126.70 & 46.64 & 5.61 & \multirow{2}{*}{$\begin{array}{l}t=-0.79 \\
d f=120 \\
p=0.43\end{array}$} \\
\hline & o & 53 & 132.76 & 35.06 & 4.81 & \\
\hline \multirow[t]{2}{*}{ VLDL } & $\hat{\sigma}$ & 68 & 32.46 & 19.34 & 2.34 & \multirow{2}{*}{$\begin{array}{l}\mathrm{t}=1.08 \\
\mathrm{df}=120 \\
\mathrm{p}=0.27\end{array}$} \\
\hline & q & 54 & 28.69 & 18.62 & 2.53 & \\
\hline
\end{tabular}

Table (3): Cholesterol- Triglyceride range values in relation to age and gender

\begin{tabular}{|c|c|c|c|c|c|c|c|c|}
\hline \multirow[t]{2}{*}{ Cholesterol } & \multirow[t]{2}{*}{ Score } & \multirow{2}{*}{$\begin{array}{l}\text { Values } \\
\text { (Mg/dl) }\end{array}$} & \multirow[t]{2}{*}{ No } & \multirow[t]{2}{*}{$q$} & \multirow[t]{2}{*}{$\hat{\sigma}$} & \multirow{2}{*}{$\begin{array}{l}\text { Mean \& age } \\
\text { range (years) }\end{array}$} & \multicolumn{2}{|c|}{$\begin{array}{c}\text { Fordyce's granules } \\
\text { (Lips and cheeks) }\end{array}$} \\
\hline & & & & & & & No & Yes \\
\hline Normal range & 0 & 109- 199 & 61 & 26 & 35 & $51(20-75)$ & 48 & 13 \\
\hline Border line & 1 & $200-239$ & 35 & 16 & 19 & $55(23-79)$ & 24 & 11 \\
\hline High level & 2 & $240-384$ & 32 & 13 & 19 & $48(22-79)$ & 24 & 8 \\
\hline Total & & & 128 & 55 & 73 & & 96 & 32 \\
\hline \multicolumn{9}{|l|}{ Triglyceride } \\
\hline Normal range & 0 & 49- 148 & 74 & 32 & 42 & $53(22-79)$ & 58 & 16 \\
\hline Border line & 1 & $150-198$ & 20 & 10 & 10 & $44.7(23-72)$ & 13 & 7 \\
\hline High level & 2 & $200-500$ & 34 & 13 & 21 & $51.4(20-79)$ & 25 & 9 \\
\hline Total & & & 128 & 53 & 73 & & 96 & 32 \\
\hline
\end{tabular}

Table (4): High density lipoprotein values in relation to age $\&$ gender

\begin{tabular}{|c|c|c|c|c|c|c|c|c|}
\hline \multirow{2}{*}{ HDL levels } & \multirow{2}{*}{ Score } & \multirow{2}{*}{ Values } & \multirow{2}{*}{ No. } & \multirow{2}{*}{ q } & \multirow{2}{*}{$\hat{\sigma}$} & \multirow{2}{*}{$\begin{array}{c}\text { Mean age range } \\
\text { (years) }\end{array}$} & \multicolumn{2}{|c|}{ Fordyce's granules } \\
\hline & & & & & & & No & Yes \\
\hline Normal range & 0 & $24-39$ & 68 & 31 & 37 & $51.8(20-79)$ & 51 & 18 \\
\hline High level & 1 & $40-78$ & 54 & 23 & 31 & $49.6(25-79)$ & 41 & 12 \\
\hline Total & & & & & & & 92 & 30 \\
\hline \multicolumn{9}{|l|}{ LDL levels } \\
\hline Normal range & 0 & $19-129$ & 63 & 27 & 36 & $52.8(20-75)$ & 48 & 15 \\
\hline High level & 1 & $130-300$ & 58 & 26 & 32 & $49.5(22-79)$ & 44 & 14 \\
\hline Total & & & & & & & 92 & 29 \\
\hline \multicolumn{9}{|l|}{ VLDL } \\
\hline Normal range & 0 & $11.5-30$ & 71 & 31 & 40 & $51.8(22-79)$ & 56 & 15 \\
\hline High level & 1 & $31-125$ & 50 & 22 & 28 & $50.7(20-79)$ & 36 & 14 \\
\hline Total & & & & & & & 92 & 29 \\
\hline
\end{tabular}


Table (5): Higher lipid profile scores in relation to Fordyce's granules

\begin{tabular}{|c|c|c|c|c|}
\hline \multirow{2}{*}{ Types of lipid } & \multirow{2}{*}{ Score } & \multicolumn{2}{|c|}{ Fordyce's granules (Lips and cheeks) } & \multirow{2}{*}{ Total } \\
\hline & & No & Yes & \\
\hline Cholesterol & 2 & 24 & 8 & 32 \\
\hline Trichleseride & 2 & 25 & 9 & 34 \\
\hline HDL & 1 & 41 & 12 & 53 \\
\hline LDL & 1 & 44 & 14 & 58 \\
\hline VLDL & 1 & 36 & 14 & 50 \\
\hline Total & & 170 & 57 & 227 \\
\hline
\end{tabular}

Table (6): Correlation Coefficient between study parameters.

\begin{tabular}{|c|c|c|c|}
\hline \multirow[t]{2}{*}{ Correlation Coefficient } & \multirow{4}{*}{$\begin{array}{l}\text { Variables } \\
\text { Cholesterol }\end{array}$} & \multicolumn{2}{|c|}{ Lips and cheeks -Fordyce account } \\
\hline & & Correlation Coefficient & $-.017-$ \\
\hline \multirow{14}{*}{ Pearson Correlation } & & Sig. (2-tailed) & .851 \\
\hline & & Number & 128 \\
\hline & \multirow{3}{*}{ Triglyceride } & Correlation Coefficient & .077 \\
\hline & & Sig. (2-tailed) & .389 \\
\hline & & Number & 128 \\
\hline & \multirow{3}{*}{ HDL } & Correlation Coefficient & $-.069-$ \\
\hline & & Sig. (2-tailed) & .446 \\
\hline & & Number & 123 \\
\hline & \multirow{3}{*}{ LDL } & Correlation Coefficient & $-.033-$ \\
\hline & & Sig. (2-tailed) & .721 \\
\hline & & Number & 122 \\
\hline & \multirow{3}{*}{ VLDL } & Correlation Coefficient & .048 \\
\hline & & Sig. (2-tailed) & .601 \\
\hline & & Number & 122 \\
\hline
\end{tabular}

\section{Discussion}

Oral Fordyce granules are often discovered during routine dental examinations. They are considered anatomic variations and are typically seen on the labial and buccal mucosa ${ }^{14,7}$.

The current study recorded FGs in $25 \%$ of the participants which is lower than what was recorded by Gaballah and Rahimi (2014) ${ }^{15}$, but it is higher than what was recorded $(7.2 \%)$ by Tortorici et al., $(2016)^{16}$ who studied the prevalence and distribution of oral mucosal non-malignant lesions.

Studies have investigated the relation of FGs with age, puberty and gender ${ }^{17,18}$. According to Choudhry, the incidence increased with age, with $60-80 \%$ of patients were elderly ${ }^{19}$. This agrees with this study which found that patients with FGs were older that those without FGs.

The current study showed that FGs were predominant in males and the majority of cases were with lips involvement, which agrees with Gorsky et al., $(1986)^{20}$ who found that lips were the most common location for these granules $(82.2 \%)$.

Also, Olivier (2006) $)^{9}$ found that FGs were mostly seen on the lips, followed by buccal mucosa, with no significant difference in the prevalence between males and females.

This completely agrees with the current study which reported that lips were the most common site, followed by cheek, but no significant difference between both gender. 
Cardiovascular disease is the most common cause of death in industrialized countries and hyperlipidemia can lead to accelerated atherosclerosis and premature death from ischemic heart disease ${ }^{21,22}$. The risk of developing atherosclerosis is directly related to the plasma LDL and inversely related to the HDL level ${ }^{23,24}$.

Although, the majority of the previous studies did not find a relation between FGs and systemic diseases (Scully, et al., 2004). In the current study, one-third of patients with systemic diseases were with FGs.

Hypertensive patients showed higher mean values of cholesterol, triglyceride, HDL and VLDL compared to patients with diabetes and those suffered from both hypertension and diabetes mellitus together. This is supported by the findings of a recent study which found that diabetes mellitus, cardiovascular disease, liver and thyroid disease could alsolead to changes in lipids profile ${ }^{25}$.

In this study, no relation was found between FGs and cholesterol, triglyceride, HDL, LDL and VLDL levels, although between $1 / 4$ and half of cases were with hyper- lipedemia were observed with FGs. This may be due to the sample size or other confounder factors.

Cases with positive FGs recorded higher means cholesterol, triglyceride and VLDL values, but lower mean values of HDL and LDL, with males showed the highest VLDL levels.

This study reported a negative correlations between FGs number and cholesterol, HDL and LDL; however, non-significant. Further studies with larger number are required to be able to discuss these findings.

Because there are many factors affecting lipid metabolism and subsequent lipid profile levels.Recent progress in molecular biology may assist researchers in the near future to identify the genes and enzymes of lipid metabolic pathways and can understand the relation between each individual lipid and FGs in the oral cavity. Up to our knowledge, no study(s) considered these relations.

To conclude, the hyperlipidemia may contribute to the appearance of the oral FGs either by the increase fatty content of clinical undetectable glands making them easily visible during the oral examination or de novo differentiation of cells leading to more oral FGs. Both explanations require confirmation studies histochemically.
The findings of this study required larger population groups with wider age groups. Due to the fact that there are many factors affecting lipid metabolism, the inclusion criteria could lead to different conclusion.

Also, dentists as care providers for the oral cavity should be aware of the importance of referring patients with high density of FGs for lipid profile tests and then for an appropriate medical care especially those with risk factors for the cardiovascular system.

Financial Disclosure: There is no financial disclosure.

Conflict of Interest: None to declare.

Ethical Clearance: All experimental protocols were approved and all experiments were carried out in accordance with approved guidelines.

\section{References}

1. Khoo LS, Cheong WK. Common genital dermatoses in male patients attending a public sexually transmitted disease clinic in Singapore. Ann Acad Med Singapore. 1995; 24(4): 505-509.

2. Woo SB. Disorders of oral mucosa. In: Barnhill RL, Crowson AN, editors. Textbook of dermatopathology. 2nd ed. New York: mcgrawHill; 2004; 999-1016.

3. James WD, Berger TG, Elston DM. Andrew's disease of the skin. Clinical dermatology. 10th Ed. Philadelphia: WB Saunders; 2006: 800

4. Lee JH, Lee JH, Kwon NH, Yu DS, Kim GM, Park CJ, Lee JD and Kim SY. Clinicopathologic Manifestations of Patients with Fordyce's Spots. Ann Dermatol. 2012; 24(1): 103-106.

5. Ahn GR, Park SJ, Lee CK and Kim BJ. A case of successful treatment of Fordyce spots with a single insulated microneedle radiofrequency device. Dermatol Ther.2019; 32(5): e13026.

6. Dreher, A and Grevers G. Fordyce spots. A little regarded finding in the area of lip pigmentation and mouth mucosa. Laryngorhinootologie. 1995; 74(6): 390-392

7. Bingisser AC, Korner M, Reichart PA and Bornstein MM. Intraoral hyperplastic Fordyce granule with destruction of bone: a case presentation. Quintessence Int 2014; 45(3): 245-248.

8. Scully C. Oral and maxillofacial medicine: the basis of diagnosis and treatment (3rd ed.). Edinburgh: 
Churchill Livingstone. 2013; 170, 392.

9. Olivier JH. Fordyce granules on the prolabial and oral mucous membranes of a selected population. SADJ. 2006; 61: 072-074

10. De Felice, C, Parrini S, Chitano G, Gentile M, Dipaola L and Latini G. Fordyce granules and hereditary non-polyposis colorectal cancer syndrome. Gut. 2005; 54(9): 1279-1282.

11. Raffy S and Teissie J. Control of lipid membrane stability by cholesterol content. Biophys J. 1999; 76(4): 2072-2080.

12. Patel, P S, Shah MH, Jha FP, Raval GN, Rawal RM, Patel MM, Patel JB and Patel DD. Alterations in plasma lipid profile patterns in head and neck cancer and oral precancerous conditions. Indian $\mathrm{J}$ Cancer. 2004; 41(1): 25-31.

13. Otis JP, Sahoo D, Drover, VA, Yen CL, Carey HV. Cholesterol and lipoprotein dynamics in a hibernating mammal. PLoS One. 2011; 6(12): e29111.

14. Bork K, Hoede N, Korting G, Burgdorf WH, Young SK. 2nd ed. Philadelphia: WB Saunders; 1996. Diseases of the Oral Mucosa and the Lips; pp. 240-1

15. Gaballah KY, Rahimi I. Can presence of oral Fordyce's granules serve as a marker for hyperlipidemia? Dent Res J (Isfahan). 2014; 11: 553-558.

16. Tortorici, S., S. Corrao, G. Natoli and P. Difalco. Prevalence and distribution of oral mucosal non-malignant lesions in the western Sicilian population." Minerva Stomatol.2016; 65(4): 191206.

17. dos Santos, PJ, Bessa CF, de Aguiar M C, do Carmo M A. Cross-sectional study of oral mucosal conditions among a central Amazonian Indian community, Brazil. J Oral Pathol Med. 2004; 33(1): $7-12$.
18. Jahanbani J, Sandvik L, Lyberg T, Ahlfors E . Evaluation of oral mucosal lesions in 598 referred Iranian patients. Open Dent J. 2009; 3: 42-47.

19. Choudhry R, Hodgins, MB, Van der Kwast TH, Brinkmann AO, Boersma W J. Localization of androgen receptors in human skin by immunohistochemistry: implications for the hormonal regulation of hair growth, sebaceous glands and sweat glands." J Endocrinol. 1992; 133(3): 467-475.

20. Gorsky M, A Fundoianu-Dayan, D. Cohen C. "Fordyce's granules in the oral mucosa of adult Israeli Jews." Community Dent Oral Epidemiol.1986; 14(4): 231-232.

21. Nash IS, Mosca L, Blumenthal RS, Davidson MH, Smith SC., Jr. and Pasternak RC. Contemporary awareness and understanding of cholesterol as a risk factor: results of an American Heart Association national survey. Arch Intern Med.2003; 163(13): 1597-1600.

22. Immanuel S, Giantini A, Dharma RS and Samino. The role of lipid profile as a risk factor indicator for ischemic stroke at Cipto Mangunkusumo Hospital, Jakarta. Acta Med Indones. 2006; 38(1): 11-16.

23. Benfante R, Reed D. Is elevated serum cholesterol level a risk factor for coronary heart disease in the elderly? JAMA. 1990; 263(3): 393-396.

24. Weverling-Rijnsburger AW, Jonkers I J, van Exel E, Gussekloo J and Westendorp RG. High-density vs low-density lipoprotein cholesterol as the risk factor for coronary artery disease and stroke in old age. Arch Intern Med. 2003; 163(13): 1549-1554.

25. Scully C, Flint SR, Porter SR, Moos KF. 3rd ed. London: Tailor and Francis Group; Oral and Maxillofacial Disease; 2004; 520.

26. Lu L, Hu C, Zhao Y, He L, Zhou J, Li H. Shotgun Lipidomics Revealed Altered Profiles of Serum Lipids in Systemic Lupus Erythematosus Closely Associated with Disease Activity. Biomolecules. 2018; 8(4). 